\title{
Ilha de Racionalidade Interdisciplinar aplicada à construção de uma representação histórica contextual sobre as máquinas térmicas
}

\section{Interdisciplinary Rationality Island applied to the construction of a contextual historical representation on thermal machines}

\author{
Geilson Rodrigues da Silva (geilsonrodrigues367@gmail.com) \\ Universidade Federal de Mato Grosso do Sul (UFMS) \\ Nádia Cristina Guimarães Errobidart (nacriguer@gmail.com) \\ Universidade Federal de Mato Grosso do Sul (UFMS)
}

\begin{abstract}
Resumo: A abordagem de ensino comumente utilizada no Ensino de Ciências privilegia a memorização de exercícios desconectada da realidade social dos estudantes. Sendo assim, uma das formas de romper com essa abordagem listada em pesquisas trata-se da utilização da Ilha de Racionalidade Interdisciplinar. Diante disso, o objetivo da presente pesquisa é desenvolver um material didático que reflete à articulação entre a metodologia da Ilha de Racionalidade Interdisciplinaridade e a abordagem Histórica Contextual para constituir uma representação que engloba diversas especialidades para o estudo da Termodinâmica. Na elaboração do material foram utilizadas a etapa de enquadrar o problema, produzir o clichê, o panorama espontâneo e abertura de caixas pretas sem ajuda de especialistas. A síntese final do processo de construção da Ilha é um material didático estruturado em 14 páginas e que demonstra a mútua influência entre ciência e a sociedade, sendo uma possibilidade para apresentar os diferentes saberes que contribuíram para o desenvolvimento da Termodinâmica.
\end{abstract}

Palavras-chave: História da Ciência; Revolução Industrial; Máquinas Térmicas.

Abstract: The teaching approach commonly used in Science Teaching favors the memorization of exercises disconnected from the social reality of students. Thus, one of the ways to break with this approach listed in research is the use of the Island of Interdisciplinary Rationality. Therefore, the aim of this research is to develop a didactic material that reflects the articulation between the methodology of the Interdisciplinarity Rationality Island and the contextual historical approach to constitute a representation that encompasses specialties for the study of Thermodynamics. In the elaboration of the material, the stage of framing the problem, producing the cliché, the spontaneous panorama and opening of black boxes without help from specialists were used. The final synthesis of the construction process of the Island is a didactic material structured in 14 pages and that demonstrates the mutual influence between science and society, being a possibility to present the different knowledge that contributed to the development Thermodynamics.

Keywords: History of Science; Industrial Revolution; Thermal Machines.

\section{INTRODUÇÃO}

A sequência discursiva de conhecimentos científicos comumente utilizada em livros didáticos e demais materiais pedagógicos e muitas vezes reproduzida por 
professores no contexto de sala de aula é pautada na desarticulação e fragmentação dos conceitos explorados. Isso pode contribuir para que os estudantes tenham dificuldades na compreensão do significado dos conhecimentos científicos que lhes são apresentados na maioria das vezes com uma valorização matemática intensa (REGIANI et al., 2012; SASSERON; DUSCHI, 2016; VIANNA; RITTER, 2019).

Essa fragmentação dificulta a discussão de problemas do mundo de forma integral (SIQUEIRA; GAERTNER, 2015) e a formação de um cidadão crítico (BRASIL, 2002; 2013), pois o estudante muitas vezes não associa o que lhe é apresentado em sala de aula com problemas complexos presentes na sociedade. Como consequência, não consegue mobilizar os conhecimentos que lhe são apresentados de forma fragmentada para conceber uma solução para tais problemas, algumas até discutidos de forma compartimentalizada nas disciplinas (FOUREZ, 1998).

Reforçamos nesse trabalho uma das possibilidades listadas na literatura da área de ensino de ciências para superar essa visão compartimentalizada do conhecimento: o envolvimento de professores e estudantes no desenvolvimento de ações interdisciplinares (REGIANI, et al, 2012; MILARÉ, 2014; MUCHENSKI, et al, 2017, SILVA e ERROBIDART, 2019). Ressaltamos que concebemos a interdisciplinaridade como importante no ensino de ciências especialmente quando almejamos realizar uma abordagem histórica conceitual. Um caminho que apresenta resultados promissores nos nossos estudos é a estruturação de ações a partir do método da Ilha de Racionalidade Interdisciplinar - IRI, proposto por Fourez e colaboradores (2008). Os resultados aqui apresentados, obtidos num estudo vinculado a uma pesquisa mais ampla, sinaliza que o método pode contribuir para com esse processo de integração, particularmente no ensino de ciências. Ele possibilita a construção de um conhecimento novo, advindo da integração e negociação de distintos pontos de vista, que pode ser construído pelo professor individualmente no decorrer da elaboração de meios e recursos pedagógicos ou na estruturação de atividades de ensino, na qual professor e alunos são os construtores da IRI.

O método IRI apresenta um conjunto de etapas que devem ser desenvolvidas e avaliadas pelos construtores da representação interdisciplinar, solicitando deles a tomada de decisões coerentes com a realidade vivenciada e associada a situação problema. A vivência de cada uma das etapas de construção da IRI promove uma forma de alfabetização científica e tecnológica dos construtores, favorecendo a percepção das 
relações existentes entre Ciência, Tecnologia, Sociedade e Meio Ambiente (SIQUEIRA; GAERTNER, 2015).

Considerando avaliar as potencialidades do método na construção de uma representação Histórico Contextual para o ensino da Termodinâmica, definimos como situação problema a abordagem do conhecimento relacionado a máquinas térmicas, integrado ao contexto social vivenciado no período da Revolução Industrial. A discussão dessa situação problema solicitou a mobilização de conhecimentos selecionados e articulados a partir do emprego do método, cuja síntese final possibilitou evidenciar a mútua influência entre a ciência e a sociedade, contribuindo para demonstrar que a atividade científica é um constructo humano fruto de dilemas, ideias, avanços e retrocessos.

\section{Fundamentação Teórica}

\subsection{O método de Ilhas de Racionalidade Interdisciplinar}

O método de Ilhas de Racionalidade Interdisciplinar quando utilizado no contexto escolar possibilita reconectar conhecimentos que se encontram fragmentados dentro de uma mesma disciplina ou em diferentes, num mesmo nível de ensino. Esse processo de reconexão dos conhecimentos passa pela elaboração de uma representação que explora aspectos cotidianos dos estudantes e que busca ressignificar uma unidade didática (SIQUEIRA; GAERTNER, 2015; SILVA; ERROBIDART, 2019).

A construção de uma representação interdisciplinar está estruturada em oito etapas não sequenciais e nem fixas, indicada na Figura 1. Nela apresentamos um esquema elaborado com base na discussão realizado por Silva e Errobidart (2019) que pontuam o emprego do método como um processo intelectual que materializa a mobilização de conhecimentos disciplinares e não disciplinares, oriundos de diferentes áreas, que pode promover a educação científica.

A Figura 1 apresenta entre cada uma das etapas propostas por Fourez (2008) e discutida pelos autores a indicação da necessidade de um momento de reflexão para avaliar a pertinência das atividades desenvolvidas e informações coletadas. A indicação no esquema faz uso de setas sobrepostas que sinalizam que dependendo do resultado dessa reflexão é possível retomar etapas anteriores, se julgarem necessário. 


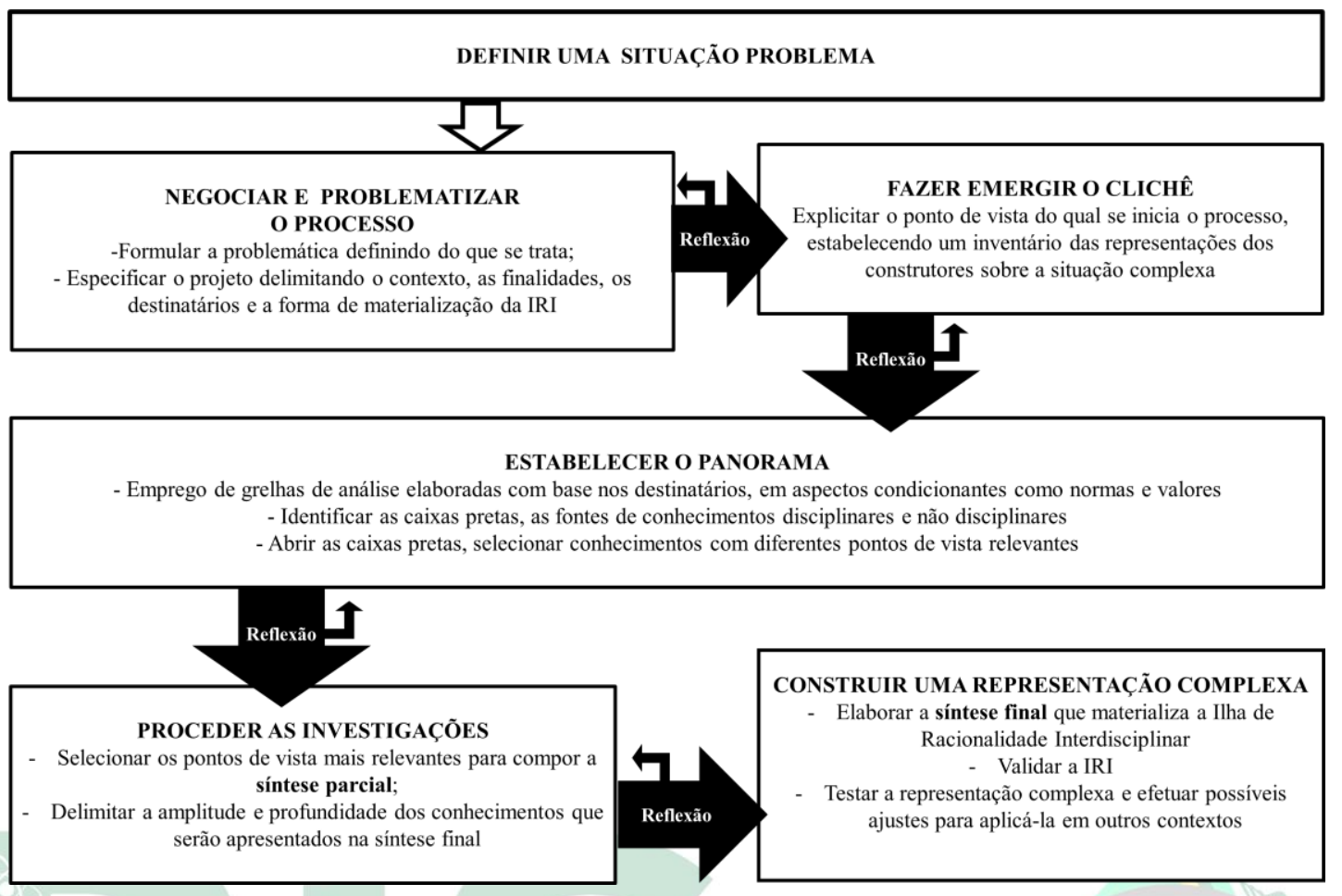

Figura 1 -Esquema do Método de Ilhas de Racionalidade Interdisciplinar.

Consideramos que essa estruturação do método com possibilidade de os construtores retomarem etapas, para inserir ou retirar conhecimentos ou pontos de vistas, segue procedimentos semelhantes ao de uma pesquisa realizada na academia. Para solucionar uma situação problema, de um projeto específico, é necessário realizar a consulta a diversas especialidades e especialistas, coletar informações, selecionar as mais relevantes e construir uma síntese, final para divulgação dos resultados (ALVESFILHO; SOUZA, 2009; SILVA; ERROBIDART, 2019).

\subsection{Abordagem Histórica Contextual}

Ao definir do que se trata a problemática que vamos explorar no projeto, no caso a abordagem do conhecimento relacionado a máquinas térmicas, integrado ao contexto social vivenciado no período da Revolução Industrial, temos que: delimitar o contexto, as finalidades os destinatários e a forma como será materializada a síntese final.

Considerando que uma das finalidades é a construção da abordagem contextual da história da ciência relacionada a esse fato histórico entendemos necessários diferenciar aspectos de uma abordagem internalista da História da Ciência dos externalistas. A primeira investiga os aspectos lógicos da construção do conhecimento científico, tais como o processo de matematização de teorias científicas e o desenvolvimento da 
experimentação. Além disso, busca analisar quais os problemas de pesquisa os cientistas tentavam responder, bem como, a interpretação deles acerca das suas descobertas, evidenciando as etapas fundamentais do processo científico. A segunda busca analisar as influências sociais, econômicas, políticas, bem como, a cultura, que estão permeando o avanço científico. Almeja modificar as concepções errôneas de que os cientistas são pessoas dissociadas do meio social e das influências econômicas e políticas. Valoriza os avanços e retrocessos do processo, como inerentes ao próprio desenvolvimento científico, evidenciando a disputa pela aceitação dos modelos científicos, entre os pares, na academia (KUHN, 2011; QUEIRÓS, 2012; MARTINELLI; MACKEDANZ, 2017).

Essa finalidade é pontuada na literatura da área de ensino como necessária e carente de materiais didáticos. Autores discutem a importância de uma abordagem contextual que destaque o empirismo pautado em evidências experimentais (internalista) e sinalizem aspectos externos a academia como a influência de fatores sociais, econômicos e políticos nas práticas científicas (TEIXEIRA, EL-HANI; FREIRE-JÚNIOR, 2001; MARTINS, 2006; EL-HANI, 2006).

Concordamos com autores que sinalizam que:

Abordagens contextuais têm sido propostas com o intuito de mudar os currículos de Ciências, em todos os níveis de ensino, propondo-se que elas podem contribuir para (i) humanizar as ciências, conectando-as com preocupações pessoais, éticas, culturais e políticas; (ii) tornar as aulas de ciências mais desafiadoras e estimular o desenvolvimento de habilidades de raciocínio e pensamento crítico; (iii) promover uma compreensão mais profunda e adequada dos próprios conteúdos científicos; (iv) melhorar a formação dos professores, ajudando-os no desenvolvimento de uma compreensão mais rica e autêntica da ciência; (v) ajudar os professores a apreciar melhor as dificuldades de aprendizagem dos alunos, alertando para as dificuldades históricas no desenvolvimento do conhecimento científico; (vi) promover nos professores uma compreensão mais clara de debates contemporâneos na área de educação com um forte componente epistemológico, a exemplo dos debates sobre o construtivismo ou o multiculturalismo (EL-HANI, 2006, p 5-6).

Assim, os aspectos listados acima enfatizam que não se busca apenas inserir uma abordagem dos processos de construção da Ciência no Ensino Médio, mas de utilizar o contexto histórico, social, filosófico e cultural na qual as atividades científicas ocorrem. Isso possibilita a participação de estudantes e docentes na investigação do processo de construção científica, que auxiliados pela metodologia da Ilha de Racionalidade Interdisciplinar possibilita a construção e implementação de propostas para o ensino sobre ciências.

\section{METODOLOGIA}


Esse trabalho apresenta os resultados de pesquisa qualitativa documental realizada para materializar a síntese final de uma representação interdisciplinar que apresenta uma proposta de uma abordagem contextual do desenvolvimento das máquinas térmicas no período da revolução industrial.

A seleção de documento para coleta das informações exploradas na síntese final, levou em consideração a etapa clichê do método IRI e os aspectos condicionantes do referencial curricular da rede estadual de ensino. Com base nisso, a coleta de informações nesses documentos, denominados por Fourez (2008) como caixas pretas, ocorreu por meio de consultas bibliográficas em artigos e livros específicos ou escritos por especialistas que estudam os temas e seus desdobramentos.

Utilizando esse documento como elemento norteador de normas e valores selecionamos informações que possibilitavam a integração de diferentes conhecimentos disciplinares, que foram fragmentados pela estrutura curricular.

O resultado dessa pesquisa forneceu um conjunto de documentos que possibilitou desenvolver a investigações que resultou no material didático pautado numa abordagem contextual, apresentado no tópico seguinte. Para construí-lo selecionamos os pontos de vista mais relevantes para compor a síntese final que foi construída, delimitando a amplitude e profundidade dos conhecimentos, de forma a ser compreensível aos destinatários: professores e alunos da educação básica.

A síntese final do processo investigativo materializa um texto com abordagem contextual histórica sobre o desenvolvimento das máquinas térmicas, no período da revolução industrial, explorando as linguagens visual e escrita.

\section{RESULTADOS E DISCUSSÕES}

Para explicitar os diferentes pontos de vista apresentados na abordagem contextual de máquinas térmicas, um conhecimento assim denominado na disciplina de Física, na sequência destacada na Figura 2, conforme no referencial curricular da rede estadual de Mato Grosso do Sul. 


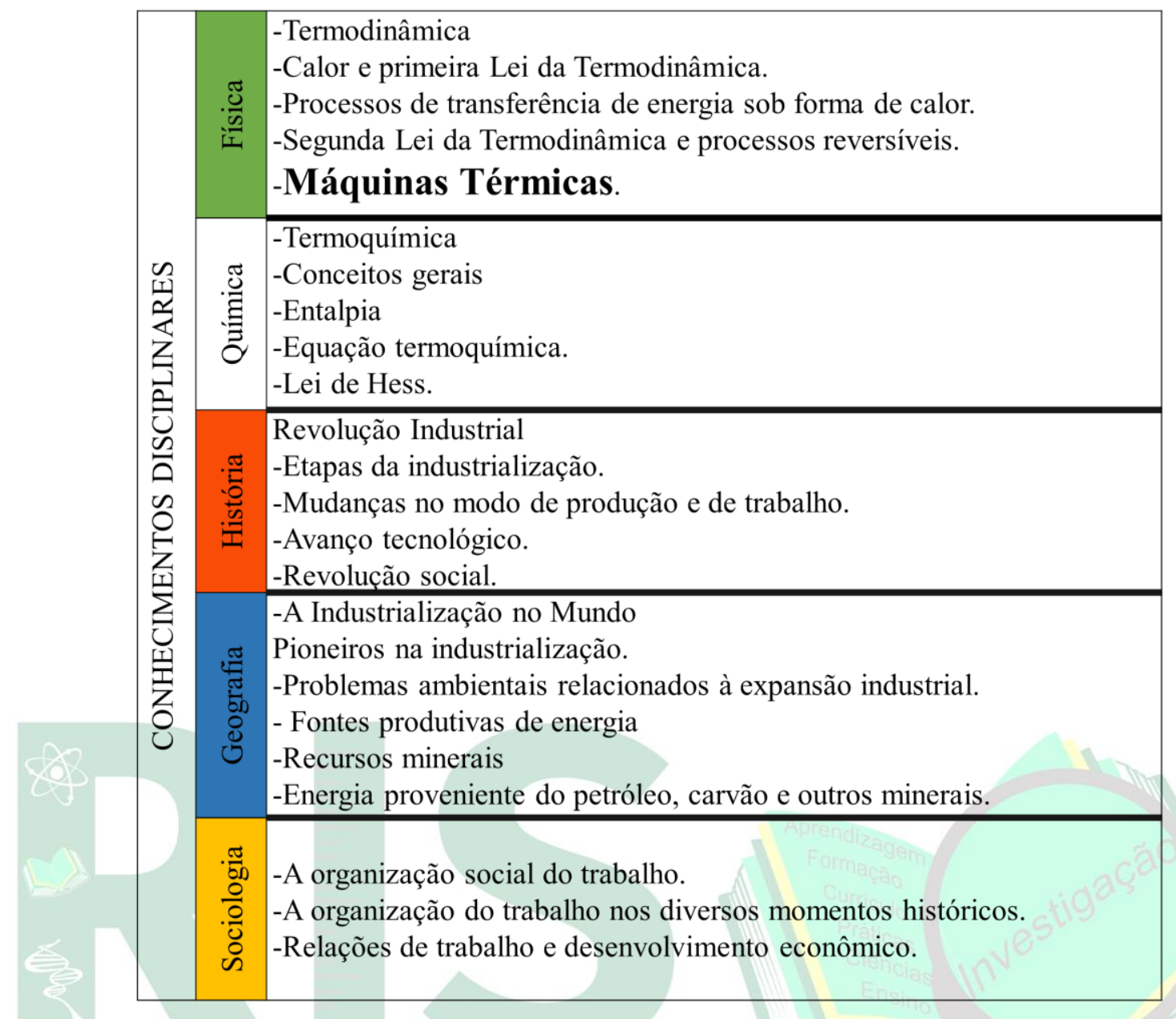

Figura 2 - Conhecimentos disciplinares evidenciados no referencial curricular do MS.

Para chamar atenção do leitor sobre a "caixa preta" que estávamos abrindo no corpo do texto, empregamos um sistema de cores: verde para a Física, branco para química, alaranjado para a História, azul para a Geografia e o ouro claro para aplicação social das máquinas térmicas - Sociologia, conforme visualizamos na Figura 2.

Ressaltamos, entretanto, que, usamos esse sistema de cores para indicar um aprofundamento da discussão principal, apresentada no corpo do texto e não para sinalizar uma fragmentação. Se essas caixas fossem suprimidas o texto continuaria apresentando uma abordagem contextual sobre o desenvolvimento das máquinas térmicas, como podemos verificar no trecho ilustrado na figura 3. 


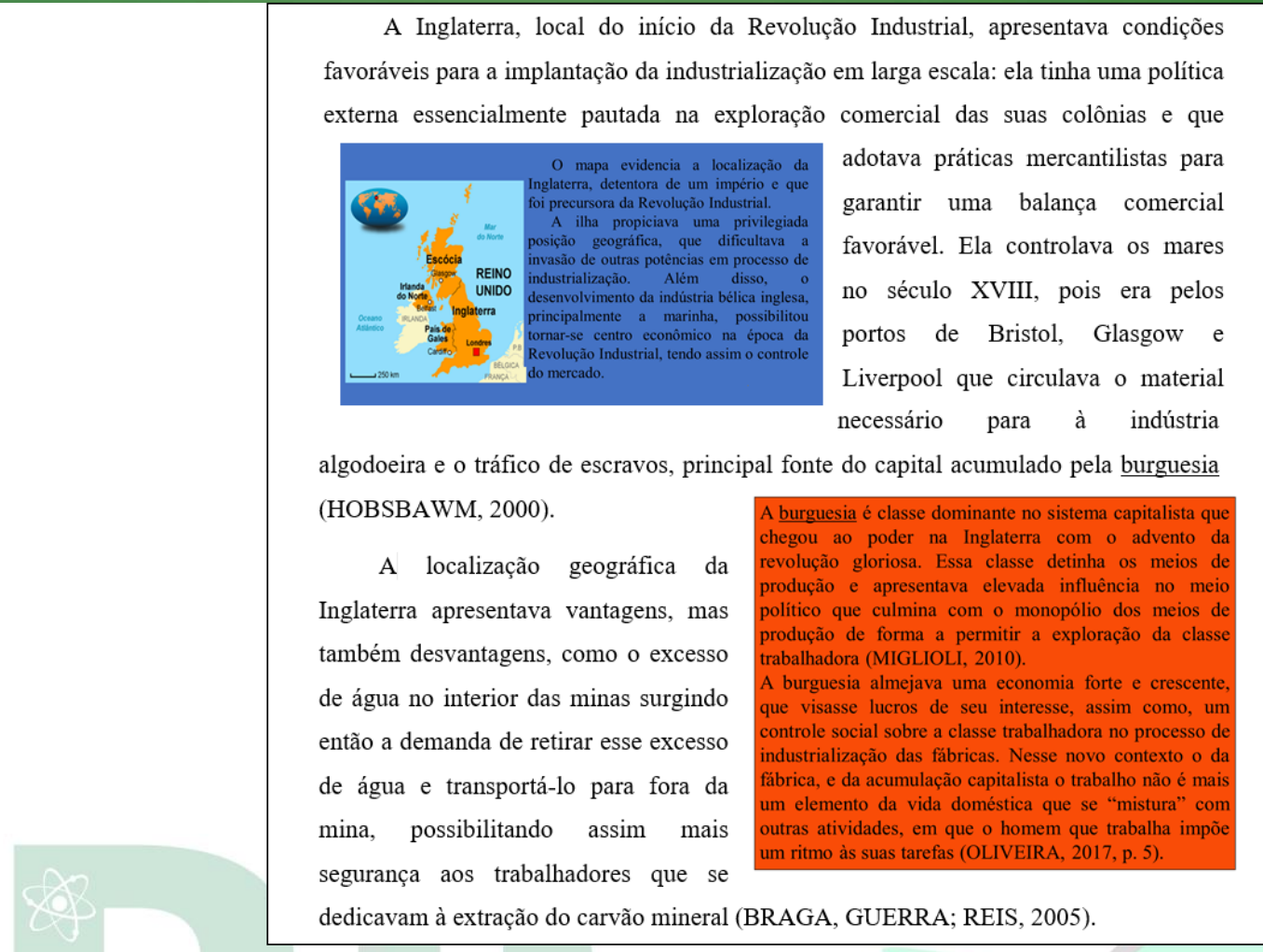

Figura 3 -

do sistema de cores utilizados para destacar os conhecimentos mobilizados.

Exemplo

As informações apresentadas na primeira caixa, ilustram a posição geográfica da Inglaterra e a localização privilegiada dos portos de Bristol, Glasgow e Liverpool, todos controlados pela Inglaterra no século XVIII. Ele, assim como o quadro que apresenta informações complementares sobre a burguesia, não comprometem a abordagem contextual histórica da síntese final da IRI, se forem retirados da discussão. Assim como as demais caixas utilizadas pelo construtor na abordagem contextual histórica do desenvolvimento das máquinas térmicas, no período da revolução industrial, foram empregadas para aprofundar o conhecimento mobilizado.

A mobilização dos conhecimentos da disciplina de Física aparece na IRI integrados aos de Sociologia, principalmente. Ao discorrer sobre o acúmulo de água no interior das minas, problema vivenciado pela Inglaterra nessa época e que impulsionou o desenvolvimento dos equipamentos denominados máquinas térmicas, apresentamos aspectos internalistas. Eles evidenciam a prática experimental como aspectos técnicos acerca do funcionamento da máquina construída e patenteada em 1698, pelo militar Thomas Savery, pioneira no processo de mecanização (figura 4) e aprimorada por Newcomem. 
A máquina de Savery era composta de uma caldeira (1), para se produzir vapor que adentrava no recipiente (2), a partir de uma tubulação com uma válvula (3). Então o vapor se condensava devido ação da água fria que era injetada na superfície do recipiente (6), com o qual se produz o vácuo parcial que é aproveitado para elevar à água do interior da mina que auxiliado pelo efeito da pressão atmosférica que atua na parte inferior (4), retirando assim a água da mina.

Essa água é transferida para o meio externo, passando pela válvula A e pela válvula (3), impulsiona a água para fora da mina por meio do vapor que é empurra sobre a superficie da água que está abrigada no recipiente (2), passando pelo duto (5), abrindo então a válvula B (SUARÉZ, 2011).

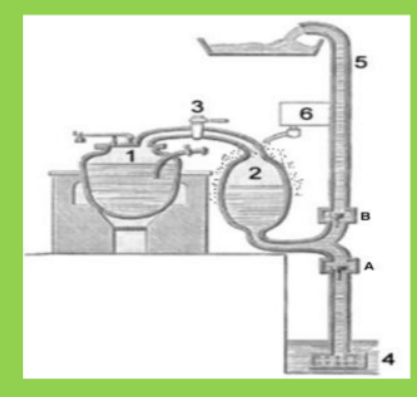

Figura 4 - Descrição do funcionamento da máquina térmica.

A Figura 4 foi inserida na síntese da IRI para complementar a discussão de aspectos internos a construção das máquinas, discorrendo sobre técnicas relacionadas ao funcionamento das máquinas. Integradas a essa discussão, ressaltamos que os inventores que estudavam essa máquina estavam interessados em aperfeiçoá-la, com o intuito de obter patentes dos inventos que propiciavam lucros elevados e que eles não realizavam essa prática com base numa interpretação dos conceitos relacionados ao estudo do calor. Essa discussão reflete uma abordagem externalista, pois explicita a necessidade social de aperfeiçoamento da máquina de Newcomem, impulsionada pela pressão comercial para aumentar a extração de minerais e baratear os custos de produção.

A máquina aperfeiçoada por Newcomem, auxiliou nas atividades realizadas pelos trabalhadores nas minas, entretanto não atendia as necessidades sociais e econômicas relacionadas a demanda de maior profundidade para extrair mais estanho, cobre, chumbo e carvão. Essa nova problemática social pressionava o desenvolvimento de novas tecnologias para retirar o excesso de água nos túneis e deixou de ser discutida apenas nas oficinas dos muitos construtores de máquinas. As discussões sobre o funcionamento e necessidade de aperfeiçoamento das máquinas térmicas também adentraram as universidades e centros de pesquisa (SANTOS, 2009).

No texto destacamos que o interesse das universidades pelas máquinas térmicas centrava-se na busca por financiamento externos para seus departamentos de engenharias e a possibilidade de competição com as sociedades científicas reais (BALDOW e JÚNIOR-MONTEIRO, 2010). A aproximação entre os profissionais das oficinas e os dos laboratórios da universidade foi impulsionada pelo fato dessas instituições de ensino e pesquisa oferecerem cursos de engenharia e possuírem oficinas mais amplas e com mais equipamentos, como a universidade de Glasgow na Escócia (TAVARES, 2008). 
$\mathrm{Na}$ universidade de Glasgow era comum a contratação de inventores para trabalharem nas oficinas dos cursos de engenharia. E uma dessas oficinas trabalhava James Watt que atuava como fabricante de instrumentos nessa universidade mesmo sem ter formação universitária ele aprendeu através da prática a sua profissão. Seu ingresso na universidade se deu graças ao apoio do seu amigo Joseph Black, importante professor de Físico-Química, que consegui autorização para James Watt utilizar as oficinas da universidade (TAVARES, 2008).

Com base nos saberes profissionais ele construiu uma máquina, buscando resolver dois principais problemas dos equipamentos que consertava: quantidade de matéria prima usada para fornecer energia para aquecer o cilindro e a perda de energia deste para o meio. Ele substituiu cilindro de ferro por um de bronze, pois esse era melhor condutor de energia na forma de calor possibilitando que o mesmo permanecesse sempre aquecido e para diminuir a perda de energia para o meio adicionou um segundo cilindro para favorecer a condensação do vapor. Com essa mudança a máquina ficou cinco vezes mais potente e reduziu em $75 \%$ o consumo de combustível (PASCOAL, 2016). No texto discutimos que a máquina aperfeiçoada por James Watt passou a ter aplicações industriais imensas, o que solicitou da burguesia altos investimentos para sua construção em larga escala. Esses investimentos renderam muito para a burguesia, aumentando a fortuna já acumulada por essa camada da sociedade inglesa.

Uma das áreas que as máquinas térmicas aperfeiçoadas por Watt tiveram destaque foi no setor militar, pois a utilização do vapor nos navios possibilitou a construção de embarcações maiores em relação aos de vela e que garantiu importantes vitórias para os ingleses contra os franceses e também permitiu o melhor controle das suas colônias dispersas pelo globo.

Na síntese final da IRI, elaborado pelo construtor, a Figura 5 foi inserida para ilustrar a importância das máquinas térmicas para vitória dos ingleses contra o império de Napoleão Bonaparte. A tecnologia empregada pelos ingleses nos navios motivou os franceses a desenvolverem novos estudos acerca do conceito de energia na forma de calor e possíveis aplicações com as máquinas.

As máquinas térmicas, desenvolvidas para solucionar a problemática do acúmulo de água nas minas, também foram empregadas na área militar. O exército utilizou-se da técnica das máquinas de Watt para as brocas canhões e e a marinha da Inglaterra para substituir a tecnologia dos navios movidos a vela, a energia dos ventos, pela as máquina a vapor. Além da eficiência relacionada ao movimento das embarcações, essa nova tecnologia possibilitou

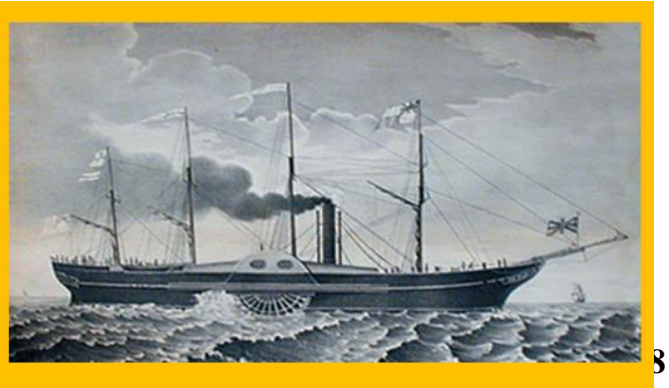


Figura 5 - Aplicação das máquinas térmicas no contexto militar.

Um dos cientistas que contribuiu para aperfeiçoar a máquina de Watt, foi Nicolas Léonard Sadi Carnot, filho de um importante militar francês Lazare Carnot Marguerite, oficial que se destacou durante a Revolução Francesa. Ele considerava importante esse aperfeiçoamento para superar o poderio militar inglês e, com base em seus estudos, evidenciou que o calor flui de um corpo que possui uma temperatura maior para outro com temperatura menor, não ocorrendo fluxo de forma inversa. Concluiu que esse aspecto é um dos principais responsáveis pelo baixo rendimento das máquinas (PASCOAL, 2016).

Outro ponto de vista explorado na síntese final da IRI, objetivou fomentar uma discussão sobre os impactos do desenvolvimento das máquinas térmicas, no período da revolução industrial, teve na sociedade inglesa. Essa discussão sobre as modificações do contexto social explorou também a influência da melhoria das máquinas térmicas utilizadas nas minas e o êxodo rural influenciado pela mecanização da mineração.

Nas cidades, os mineradores que vieram do interior aumentavam as filas de desempregados, aumentando a oferta de mão de obra para as fábricas, aspecto que resultou na sua exploração por parte da burguesia, que oferecia um baixo salário aos trabalhadores (HOBSBAWM, 2000). Além disso, essas fábricas funcionavam com jornadas de trabalho em torno de 16 a 18 horas incluindo preferencialmente mulheres e as crianças como ilustrado na figura 6 (VINCENTINO; DORIGO, 2013).

A Figura 6 ilustra como esses equipamentos modificaram a sociedade e as relações no mundo do trabalho. 


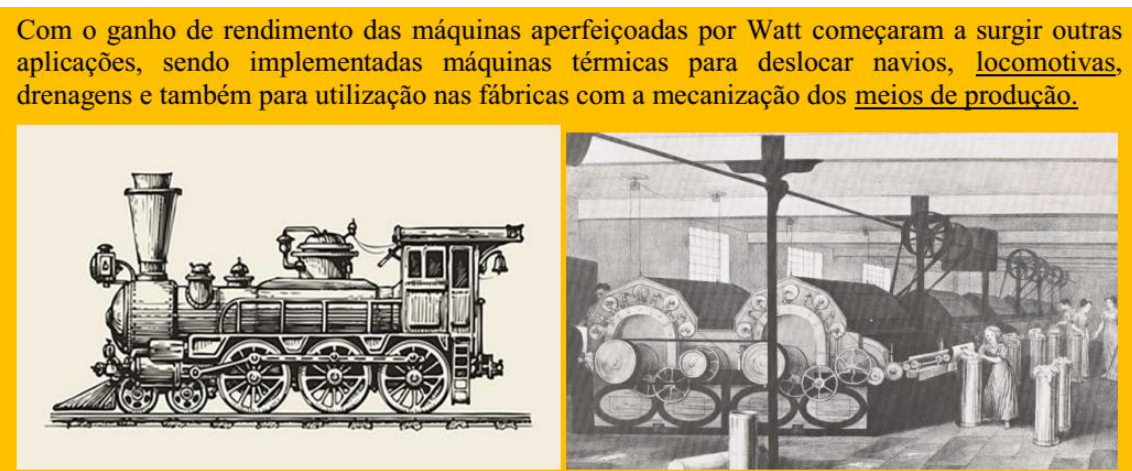

\begin{abstract}
As utilizações das máquinas térmicas foram fundamentais para mudanças nas relações de trabalho ao impor o modo de produção em larga escala e também para aumentar a produtividade. Além disso, os industriais passaram a demitir os trabalhadores homens e preferirem o emprego da mão de obra infantil e de mulheres. Sendo que ambos passaram a buscar ocupação profissional para complementar a renda da família que foi reduzida com a demissão dos trabalhadores adultos do sexo masculino. Devido ao desemprego acelerado e a oferta de mão de obra abundante, os salários pagos aos trabalhadores tornaram-se muito abaixo do mínimo para a sobrevivência.
\end{abstract}

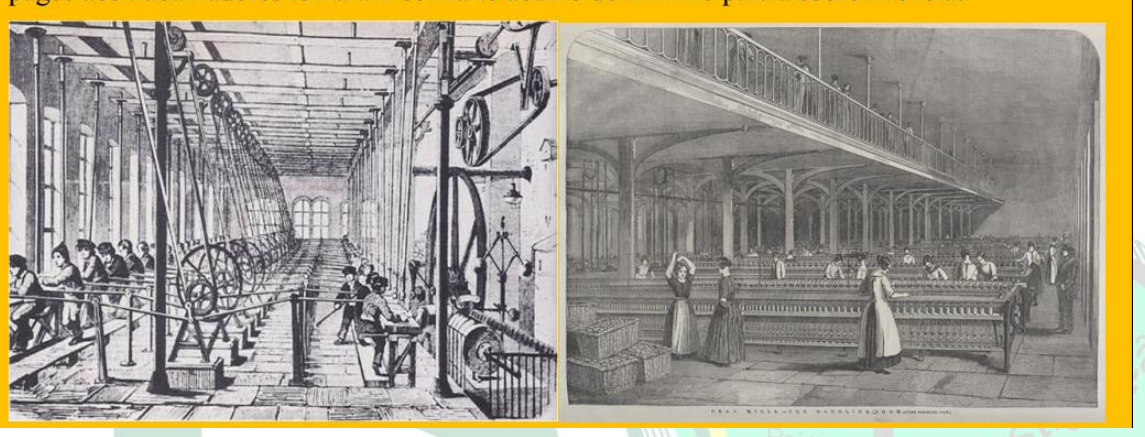

Figura 6 - Ilustração do emprego de máquinas térmicas na sociedade.

É importante ressaltar que esses são alguns dos conhecimentos mobilizados nas

14 páginas da síntese final construída pelos pesquisadores. A sua materialização representa uma das formas de apresentar as informações coletadas no processo investigado pautado na pesquisa documental estruturada pelo método de Fourez (2008).

Essa síntese final representa uma possibilidade de reconectar os conhecimentos disciplinares dispersos na matriz curricular e muitas vezes não explorados pelos professores das disciplinas listadas na figura 2 e uma possibilidade de realizar uma abordagem contextual do desenvolvimento das máquinas térmicas no período da revolução industrial.

\title{
5. CONSIDERAÇÕES FINAIS
}

A representação interdisciplinar materializada num texto com abordagem histórica contextual, construída com base no emprego do método de Ilhas de Racionalidade Interdisciplinar, materializa a integração de conhecimentos disciplinares relacionados ao desenvolvimento das máquinas térmicas no período da revolução 
industrial. Sua construção explicita a produção do conhecimento científico, possíveis fontes de influência e marcas do contexto social e cultural em que foi desenvolvido.

Resultados já analisados sinalizam a potencialidade do material na discussão de relações entre a Ciência, Tecnologia e a Sociedade no contexto da educação básica. Apresenta uma abordagem que possibilita a compreensão de que os cientistas não vivem em um mundo à parte e que o empreendimento científico é uma atividade humana, influenciada por outras ideias e outros cientistas, isso possibilita conhecer os processos que constituem o fazer científico e não somente os produtos finais da ciência.

\section{REFERÊNCIAS}

ALVES-FILHO, J, de P; SOUZA, F, N. Analisando os padrões de questionamento presentes na Ilha Interdisciplinar de Racionalidade de Fourez. In: Encontro Nacional de Pesquisa em Educação em Ciências. Anais. Florianópolis: ENPEC, 2009. p. 1-12.

BALDOW, R.; MONTEIRO-JÚNIOR, F, N. Os livros didáticos e suas omissões e distorções na História e no desenvolvimento da Termodinâmica. Alexandria Revista de Educação em Ciência e Tecnologia. v.3, n.1, p. 3-19, 2010.

BRAGA, M.; GUERRA, A.; REIS, J.C. Surge um novo mecanismo: A máquina a vapor. In: Breve História da Ciência Moderna. Das luzes ao sonho do doutor Frankenstein (século. XVIII) -Col. Breve História da Ciência Moderna, v.3, ed. Rio de Janeiro: Jorge Zahar Editor, 2005, p. 29-38.

BRASIL. MEC. PCN+: Orientações Educacionais complementares aos Parâmetros Curriculares Nacionais: Ensino Médio. Brasília: MEC/SEMTEC, 2002.

BRASIL. MEC. Diretrizes Curriculares Nacionais Gerais da Educação Básica. Ministério da Educação. Secretaria de Educação Básica. Diretoria de Currículos e Educação Integral. Brasília: MEC, SEB, DICEI, 2013.

EL-HANI, C, N. Notas sobre o ensino de História e Filosofia da Ciência Na Educação Superior. In: SILVA, C.C. (ORG). História e Filosofia da Ciência no Ensino de Ciências: Da teoria à sala de aula. São Paulo (Brasil): Editora Livraria da Física, p. 321, 2006.

FOUREZ, G. A interdisciplinaridade em sentido estrito. In: FOUREZ, Gérard; MAINGAIN, A, DUFOUR, B. Abordagens didácticas da interdisciplinaridade. Lisboa: Instituto Piaget, 2008 Cap. V, p. 69 -80.

HOBSBAWM, E, J. Da Revolução Industrial inglesa ao imperialismo. Tradução: Donaldson Magalhães Garschagen. 5 ed. Rio de Janeiro: Forense Universitária, 2000. 
KUHN, T, S. A tensão essencial. Tradução: Marcelo Amaral Penna-Forte. Rio Claro: Editora Unesp, 2011.

MARTINELLI, N, R.B.; MACKEDANZ, L, F. Abordagens da História da Ciência no Ensino de Ciências. In: Encontro Nacional de Pesquisa em Educação em Ciências. Anais. Florianópolis: ENPEC, 2017. p. 1-9.

MARTINS, R. de. A. Introdução a História das Ciências e seus usos na educação. (pp. 21-34). In: Silva, C, C. (ed.). Estudos de história e filosofia das ciências: subsídios para aplicação no ensino. São Paulo: Livraria da Física, 2006.

MILARÉ, T. A proposta metodológica de Ilha Interdisciplinar de Racionalidade em um curso de Licenciatura em Química: Discutindo informações de corrente de E-mail. Química Nova na Escola. v. 36, n.2, p. 126-134, 2014.

MIGLIOLI, J. Dominação burguesa nas sociedades modernas. Crítica Marxista. v.22, s/n, p. 13-31, 2010.

MUCHENSKI, J, C. et al. Proposta de aprender por projetos de pesquisa alicerçados por Ilhas Interdisciplinares de Racionalidade. In: Encontro Nacional de Pesquisa em Educação em Ciências. Anais. Florianópolis: ENPEC, 2017. p. 1-9.

OLIVEIRA, R, M, de. Revolução Industrial na Inglaterra: Um Novo Cenário na Idade Moderna. Revista Científica Multidisciplinar Núcleo do Conhecimento. v.1, n.2, p 89-116, 2017.

PASCOAL, A, dos, S. A evolução histórica da máquina térmica de Carnot como proposta para o Ensino da segunda lei da Termodinâmica. 2016. 142f. Dissertação de Mestrado em Ensino de Ciências e Educação Matemática, Centro de Ciências e Tecnologia, Universidade Estadual da Paraíba, Campina Grande, 2016.

QUEIRÓS, W, P. A articulação das culturas humanísticas e científicas por meio do estudo histórico-sociocultural dos trabalhos de James Prescott Joule: Contribuições para a formação de professores universitários em uma perspectiva transformadora. 2012. 355 p. (Tese de doutorado em Educação para Ciências, Faculdade de Ciências, Universidade Estadual Paulista), Bauru, 2012.

REGIANI, A, M. et al. Seguindo os passos de Sherlock Holmes: Experiência Interdisciplinar em encontro de divulgação científica. Ensaio. v.14, n.3, p. 185-198, 2012.

SANTOS, Z, T, S, dos. Ensino de Entropia: Um enfoque histórico e epistemológico. 2009. 166 f. Tese de doutorado em Educação, Centro de Ciências Sociais e Aplicadas, Universidade Federal do Rio Grande do Norte, Natal, 2009. 
SASSERON, L, H.; DUSCHI, R, A. Ensino de Ciências e as práticas epistêmicas: O papel do professor e o engajamento dos estudantes. Investigações em Ensino de Ciências. v.21, n.2, p. 52-67, 2016.

SIQUEIRA, J, B.; GAERTNER, R. Ilhas de Interdisciplinares de Racionalidade: Conceito de proporcionalidade na compreensão de informações contidas em rótulos alimentícios. Revista Brasileira de Ensino de Ciências e Tecnologias. v. 8, n. especial, p. 160-175, 2015.

SILVA, G. R. da.; ERROBIDART, N, C, G. Elaboração de uma representação interdisciplinar da História da Termodinâmica. Areté- Revista Amazônica de Ensino de Ciências. v. 12, n. 25, p. 55-71, 2019.

SUÁRES, M, J. Estudio del impacto de los conceptos fundamentales de la Termodinámica em el desarrollo de la máquina térmica y el surgimento de la revolución industrial. 2011. 75f. Maestría em Enseñanza de las ciencias exactas y naturales. Facultad de Ciencias, Universidad Nacional de Colombia, Medellin, 2011.

TAVARES, L, A. James Watt: A trajetória que levou ao desenvolvimento da máquina a vapor vista por seus biógrafos e homens de ciências. 2008. 74 f. Dissertação de Mestrado em História da Ciência, departamento de Educação, Pontifica Universidade Católica de São Paulo, São Paulo, 2008.

TEIXEIRA, E, S.; EL-HANI, C, N.; FREIRE-JÚNIOR, O. Concepções de estudantes de física sobre a natureza da ciência e sua transformação por uma abordagem contextual do ensino de ciências. Revista Brasileira de Pesquisa em Educação em Ciências, v. 1, n. 3, 2001.

VIANNA, N, S.; RITTER, J. O que diz a literatura Brasileira em relação ao Currículo de Química. Revista Insignare Scientia. v. 2, n.1, p. 32-49, 2019.

VinCEntino, C.; DORIGO, G. História Geral e do Brasil. 2 ed. São Paulo: Scipione, 2013. 